\section{STRUCTURE WITHIN THIN EPOXY FILMS REVEALED BY SOLVENT SWELLING: A NEUTRON REFLECTIVITY STUDY}

\author{
M. S. Kent, H. Yim, W. McNamara, \\ Sandia National Laboratories, Albq NM \\ R. Ivkov, S. Satija, \\ NIST Gaithersburg, MD. \\ J. Majewski \\ Los Alamos Nat. Lab., Los Alamos, NM

\section{INTRODUCTION}

Due to a variety of factors, the structure and properties of polymer films can be different near interfaces compared to the bulk. At a substrate surface, polymer mobility is generally restricted due to adsorption of segments, restricted conformations, segment layering, alignment of chains, and decreased free volume. ${ }^{1,2}$ At the air surface of glassy polymers, mobility is typically increased relative to the bulk. ${ }^{3.4}$ In multicomponent systems, preferential segregation can occur at either interface due to both enthalpic and entropic effects. ${ }^{5}$

Structure near a substrate surface is important for stress transfer, mechanical properties, fracture mechanisms, and diffusion of penetrants, among others. Structure at the air surface can impact surface reconstruction, surface free energy, wettability, and reactivity. In addition, structural gradients at air surfaces can impact the interfacial strength that develops when contacted with a second polymer. This is particularly important in technological applications involving thermosets such as multilayer paint films, and manufacturing processes involving multiple adhesives and encapsulants which come into contact.

The focus of this work is the structure within highly crosslinked, two component epoxy films. We examine variations in crosslink density within thin (600-1200 $\AA$ ) epoxy films on silicon substrates by solvent swelling. ${ }^{6}$ The method is based on the fact that the equilibrium volume fraction of a swelling solvent is strongly dependent upon the local crosslink density. We examine the volume fraction profile of the good solvent nitrobenzene through the epoxy films by neutron reflection. Isotopic substitution is used to provide contrast between the epoxy matrix and the swelling solvent.

\section{EXPERIMENTAL}

Materials. Research grade EPON 828 epoxy resin was obtained from Shell Chemical Co. The resin was cured with an aliphatic polyethertriamine ( $\mathrm{T} 403$, Huntsman Chemical). Both resin and crosslinker were used as received. The silicon wafers used as substrates in this study were polished 2-inch diameter single crystals (111) obtained from Semiconductor Processing Co. Nitrobenzene-d5 (d-NB, 99.5 atom \% D) was obtained from Aldrich and used as received.

Procedures. The wafers were cleaned using the "RCA" process: a sulfuric acid/hydrogen peroxide clean, followed by etching in an HF solution, and then the regrowth of silicon oxide with ammonium hydroxide/hydrogen peroxide solution. Three samples were prepared by spin coating $(36,46$, and $56 \mathrm{phr}$ - parts T403 per hundred parts resin), and cured at $50{ }^{\circ} \mathrm{C}$ for $48 \mathrm{hrs}$. The surface tensions of the liquid epoxy resin, crosslinker, and resin/crosslinker mixtures were measured by the Wilhelmy plate technique using a sand-blasted platinum plate and a Q11 force transducer from Hottinger Baldwin Measurements. Neutron reflectivity (NR) measurements were performed on the NG7 reflectometer (NIST). The method of NR is described in detail elsewhere. ${ }^{7}$ NR allows the determination of the neutron scattering length density (SLD) profile normal to the substrate surface, which is determined by the density and atomic composition. During the NR measurements, the samples were maintained at room temperature in a sealed aluminum chamber. The reflectivity of an as-prepared sample was first measured with desiccant in the chamber. The desiccant was then removed and the chamber was saturated with d-NB, a good solvent for both the resin and the crosslinker. Since the surface tension of $d-N B$ $(\sim 44 \mathrm{dyne} / \mathrm{cm})$ is higher than that of the mixtures of epoxy resin and T403 $(\sim 33-35$ dyne/cm), a wetting layer of d-NB does not form on the surface of the epoxy film. This was important since the neutron beam was directed onto the interface from the air side. Equilibrium saturation of $\mathrm{d}-\mathrm{NB}$ within the films was confirmed by measuring the reflectivity with time until the reflectivity curve did not change.

\section{RESULTS}

Reflectivity from a $46 \mathrm{phr}$ sample as-prepared and after swelling to equilibrium with $\mathrm{d}-\mathrm{NB}$ is shown in 


\section{DISCLAIMER}

This report was prepared as an account of work sponsored by an agency of the United States Government. Neither the United States Government nor any agency thereof, nor any of their employees, make any warranty, express or implied, or assumes any legal liability or responsibility for the accuracy, completeness, or usefulness of any information, apparatus, product, or process disclosed, or represents that its use would not infringe privately owned rights. Reference herein to any specific commercial product, process, or service by trade name, trademark, manufacturer, or otherwise does not necessarily constitute or imply its endorsement, recommendation, or favoring by the United States Government or any agency thereof. The views and opinions of authors expressed herein do not necessarily state or reflect those of the United States Government or any agency thereof. 


\section{DISCLAIMER}

Portions of this document may be illegible in electronic image products. Images are produced from the best available original document. 
Figure 1a. The reflectivity for the as-prepared sample shows strong oscillations which persist to the highest values of $q$ examined. This indicates that the epoxy film is quite smooth. The curve through the data for the as-prepared sample corresponds to the best-fit using a single layer profile for the epoxy film shown by the solid line in Figure 1b. The SLD is consistent with that calculated from the atomic composition and the bulk density. The roughness at the air surface

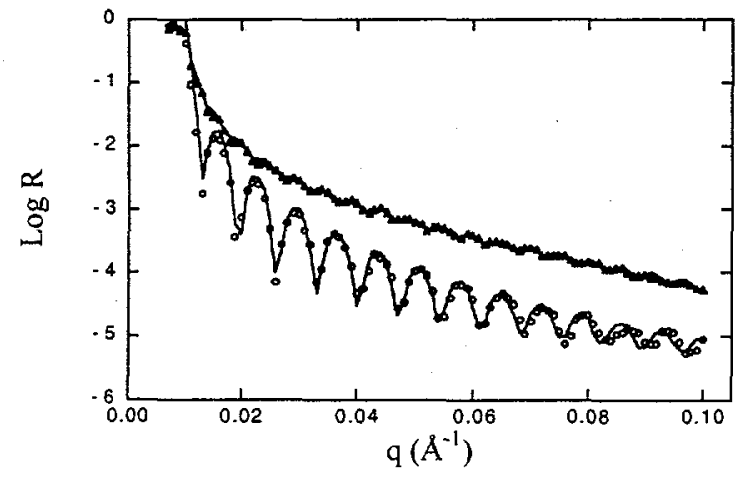

Figure 1a. Neutron reflectivity from a $46 \mathrm{phr}$ sample as-prepared and after swelling to equilibrium with d-NB.

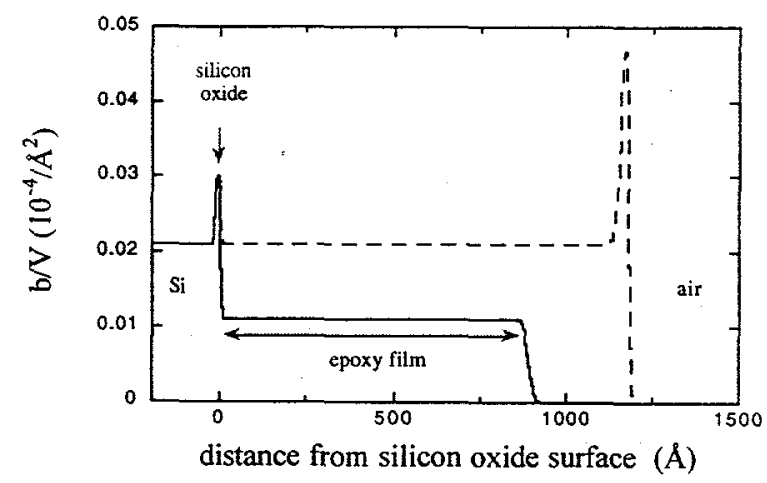

Figure 1b. Best-fit SLD profiles corresponding to the curves through the data in (a) for the sample as-prepared $(-)$ and after swelling (--).

corresponds to $\sigma=4 \AA$, where $\sigma$ is defined as the root mean square (rms) value of the deviation of the height relative to the average height of the surface. This simple model is entirely adequate to describe the data for the as-prepared sample. Similar profiles were also adequate for the as-prepared $36 \mathrm{phr}$ and $56 \mathrm{phr}$ samples. In each case, the reflectivity data could be described using a single-step profile with roughness at the air surface comparable to that for the $46 \mathrm{phr}$ sample.

In Figure 1a, the $46 \mathrm{phr}$ sample swollen with dNB shows a large increase in reflectivity relative to the data for the as-prepared sample. The increase is due to adsorption of d-NB. The best-fit SLD profile for the d-NB swollen sample is also shown in Figure 1b. The thickness and SLD of the swelled film have both increased substantially relative to that of the asprepared film. More importantly, in contrast with the results for the as-prepared sample, the reflectivity for the swelled sample is not consistent with a single layer profile, but rather increased SLD is required at the air surface. This indicates excess d-NB, and thus a lower crosslink density in the region near the air surface. This effect is due to preferential segregation of the polyetheramine crosslinker to the air surface. Segregation of T403 to the air surface is expected based on the surface tensions of the resin $(47.8$ $\mathrm{mN} / \mathrm{m})$ and the crosslinker $(33.5 \mathrm{mN} / \mathrm{m})$. The surface tensions for the 36,46 and 56 phr mixtures were measured to be $36.7,35.2,34.0 \mathrm{mN} / \mathrm{m}$, respectively. The fact that the surface tensions of the mixtures are close to the value for pure $\mathrm{T} 403$ verifies that the surface is rich in T403. Segregation of low surface energy components to the air surface has been studied extensively in other multicomponent polymer films. ${ }^{5}$

Figure 2a compares NR data from 36,46 , and 56 phr films after swelling to equilibrium with $d-N B$. The SLD profiles are shown in Figure $2 b$. Note that the form of the reflectivity curve is different for each

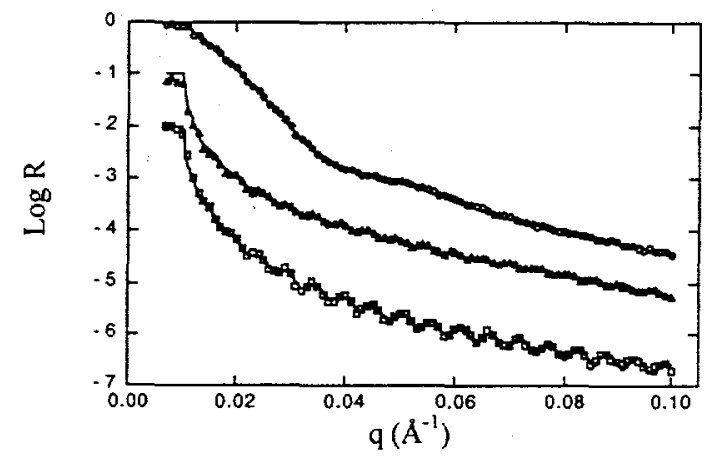

Figure 2a. Neutron reflectivity from $36(0), 46(\Delta)$, and 56() phr samples after swelling to equilibrium with $d-N B$. The data are shifted on the $y$-axis for clarity.

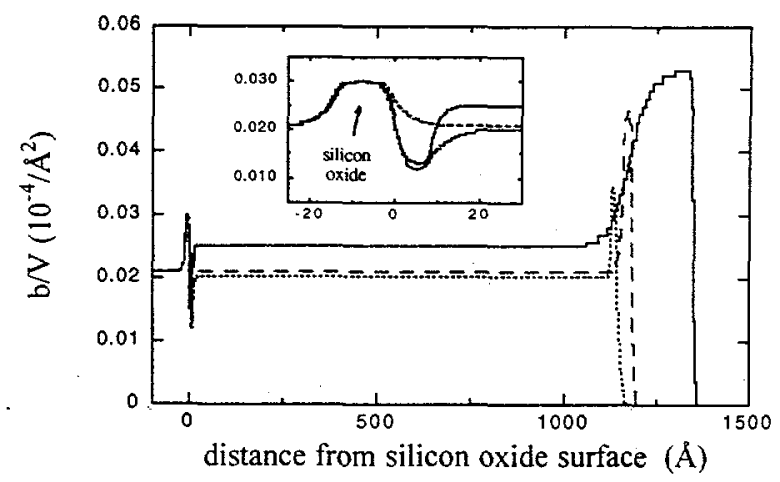

Figure $2 \mathrm{~b}$. Best-fit SLD profiles corresponding to the curves through the data in (a) for $36(-), 46(---)$, and $56(\ldots)$ phr samples. 
film. These data reveal several important differences in the structure of the epoxy films. For the $36 \mathrm{phr}$ film the reflectivity curve shows very high reflectivity at low $\mathrm{q}\left(0.01 \AA^{-1}<\mathrm{q}<0.04 \AA^{-1}\right)$. Without any detailed analysis, the enhanced reflectivity at low $q$ for the $36 \mathrm{phr}$ film is a clear indication of much greater absorption of d-NB near the air surface. The magnitude of this effect for the three compositions occurs in the following order: $36 \mathrm{phr}>>46 \mathrm{phr}>56$ phr. This trend can be understood by considering the composition perturbation near the air surface to consist of two layers as illustrated in Figure 3: an excess of $\mathrm{T} 403$ immediately at the air surface followed by a layer which we refer to as the "nearsurface" layer which is depleted of T403. A $36 \mathrm{phr}$ film would be deficient in $\mathrm{T} 403$ if resin and crosslinker were uniformly distributed. Strong segregation of $\mathrm{T} 403$ to the air surface leaves the nearsurface region even further depleted of $\mathrm{T} 403$. This

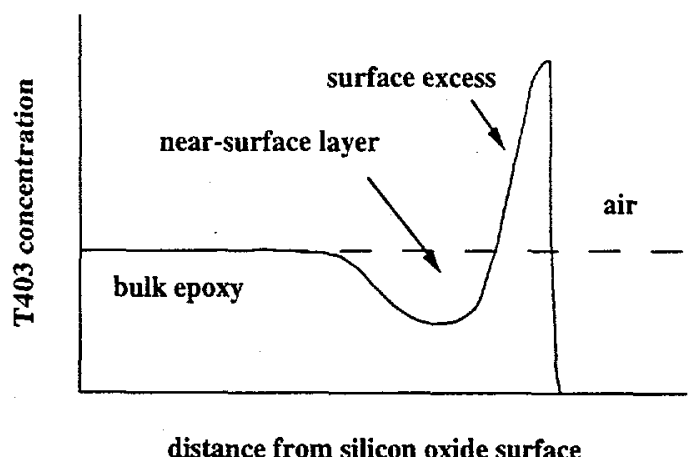

Figure 3. Qualitative illustration of the composition perturbation near the air surface. Strong segregation of the cross-linker to the air surface likely leads to a depletion of cross-linker in the near surface region.

leads to a highly imperfect network and a high degree of swelling over a relatively large length scale. With the $46 \mathrm{phr}$ sample, preferential segregation of $\mathrm{T} 403$ also leads to a depletion of $\mathrm{T} 403$ in the near-surface region, however the composition will be much closer to the stoichiometric ratio and thus the network is not nearly as imperfect. With the 56 phr sample, T403 would be in excess if resin and crosslinker were uniformly distributed. Depending upon the degree of preferential segregation of $\mathrm{T} 403$, the composition in the near-surface layer may actually approach the stoichiometric ratio. Thus, the surface region swells the least in this case, due primarily to the excess T403 immediately at the surface.

As shown in the inset of Figure $2 b$, a thin region of low SLD is detected near the silicon oxide surface for the 36 and $56 \mathrm{phr}$ films. This indicates exclusion of $d$-NB from the region immediately adjacent to the substrate surface, apparently due to strong binding between epoxy and the native silicon oxide. For the $46 \mathrm{phr}$ film, the sensitivity to this feature is very low, such that a clear determination about the presence of this layer cannot be made.

\section{CONCLUSIONS}

NR from epoxy films swelled with d-NB reveals variations in SLD at both the air surface and at the silicon substrate surface. The main effect is excess swelling of d-NB at the air surface, which was observed for all the films. This is due to preferential segregation of the crosslinker to the air surface. The degree of excess swelling at the air surface depends strongly on the nominal composition. To our knowledge, this effect has not been previously reported, and may have important implications for multilayer paint films and other applications where thermosetting films are deposited and cured sequentially. A thin $(\sim 10-20 \AA)$ layer depleted of $d$ $\mathrm{NB}$ at the substrate surface is also required to fit the NR data for the 36 and $56 \mathrm{phr}$ films. The depletion of $\mathrm{d}-\mathrm{NB}$ may be due to strong binding between the epoxy and the substrate. Large length-scale variations in crosslink density, such as have been reported at interfaces of epoxy with aluminum, ${ }^{8}$ were not observed at the silicon oxide surface.

\section{References}

1. Muller-Buschbaum, P.; Gutmann, J.S.; Lorenz, C.; Schmitt, T.; Stamm, M. Macromolecules 1998, 31, 9265.

2. Zheng, X.; Rafailovich, M.H.; Sokolov, J.; Strzhemechny, Y.; Schwarz, S.A.; Sauer, B.B.; Rubinstein, M. Phys. Rev. Lett. 1997, 79, 241.

3. Rouse, J.H.; Twaddle, P.L.; Ferguson, G.S. Macromolecules 1999, 32, 1665.

4. Forest, J. A.; Dalnoki-Veress, K.; Stevens, J. R.; Dutcher, J. R. Phys. Rev. Lett. 1996, 77, 2002.

5. Hester, J.F.; Banerjee, P.; Mayes, A.M. Macromolecules 1999, 32, 1643.

6. Yim, H.; Kent, M.; McNamara,W.F.;Ivkov, R.;Satija, S.;Majewski, J. Macromolecules 1999, 32, 7932.

7. Russell, T. P. Mater. Sci. Rep. 1990, 5, 171.

8. Arayasantiparb, D.; Siangchaew, K.; Libera, M.; McKnight, S. Micros. Microanal. 1997, 3 (Suppl. 2), 543. 